\title{
Third Party Disability among Spouses of People with Hearing Loss
}

\author{
Valli Rajasekaran, ${ }^{1}$ Preeti Rajasekaran ${ }^{1}$
}

\begin{abstract}
Introduction
With increasing life expectancy globally, hearing loss has become a major issue of concern. In addition to the negative implications on the people with hearing loss, it is also found to have a significant negative impact on the communication partners especially the spouse. Understanding the impact of hearing loss on their partners can aid us in addressing these issues during rehabilitation.

Materials And Methods

A cross sectional study was conducted among 60 people who presented with hearing loss and were living with their spouse. The hearing loss was assessed using pure tone audiometry. The third party disability among the spouses was assessed by using HIISOP questionnaire. The disability scores were calculated and correlated with the severity of hearing loss using chi square test. $\underline{\text { Result }}$

The hearing loss was associated with some degree of third party disability (58.3\%). The degree and duration of hearing loss did not correlate with the degree of third party disability. Female significant others had more difficulty than the male significant others. However, increasing age of the spouse, longer duration of married life and presence of chronic illness in the spouse were associated with more third party disability.

Conclusion

Hearing loss causes third party disability among spouses. In addition to treating hearing loss, the health care professionals should involve the spouses in treatment and rehabilitation. This highlights the need for family centred policies in treatment of hearing loss.

$\underline{\text { Keywords }}$

Hearing Loss; Spouses; Disability; Cross-Sectional Studies
\end{abstract}

$\underline{\text { ABSTRACT }}$

$\mathrm{H}$ earing loss is one of the neglected chronic conditions. Hearing loss is the second most common cause of disability ${ }^{1}$ and accounts for about $4.7 \%$ of total years lived with disability. ${ }^{2}$ About 63 million people in our country suffer from significant auditory loss. ${ }^{3}$

The health condition of a patient causes disability among the family members which is referred to as third party disability. ${ }^{4}$ Hearing loss related quality of life is impaired in spouses in spite of them having no hearing deficit. The activity limitation and participation restriction experienced by spouses of people with hearing impairment can be called as third party disability according to the World Health Organisation's (WHO) International Classification of Functioning, Disability, and Health(ICF). ${ }^{5}$

The hearing loss of the spouse has a significant impact on them in numerous ways. The negative consequences of hearing impairment take a greater toll on the spouses than among other relatives. ${ }^{6}$ Studies on spouses have shown that they experience embarrassment and communication breakdown in social situations in turn leading to reduced social interactions, making them more worried and anxious. The additional effort made by the spouses to communicate effectively can lead to physical exhaustion. ${ }^{7}$ On the other hand there are also some positive effects on relationship like improved communication skills, development of more patience and better understanding of needs of people with hearing impairment. ${ }^{8}$ Hearing loss can have significant negative

1 - Department of ENT, Shri Sathya Sai Medical College and Research Institute, Tiruporur, Chengalpet, Tamilnadu

Corresponding author:

Dr Valli Rajasekaran

email: vallivinothkumar11@gmail.com 
impact on themselves and their family members. In addition to the communication problems, the need for increased emotional support and communicative assistance creates distress for the family members. The altered social and emotional health experienced by spouses can in turn add on to the disability of hearing impaired. The family members influence their health seeking behaviour and adherence to treatment or rehabilitation. The impact of hearing loss on the family members has been less studied. Understanding the changes in the physical, social and emotional health of the spouses can help us in focusing on these aspects of health as well and may help us in providing holistic care for the patients with hearing loss.

This study was done to determine the third party disability in spouses of people with hearing impairment and to correlate the severity of third party hearing disability with degree and duration of hearing loss.

\section{Materials and Methods}

A cross sectional study was done in our medical college from July 2018 and August 2018 among 60 patients who presented to ENT OPD with hearing loss, irrespective of the type of hearing loss for more than 6 months. People with more than $25 \mathrm{db}$ hearing loss, age more than 18 years, who are married and living with their spouse and spouse having normal hearing were included in the study. People with cognitive impairment and spouses with self reported dementia or cognitive impairment were excluded from the study.

\section{Data collection:}

The study was conducted after clearance from the Institutional Ethics Committee in May 2018. Patients attending ENT OPD with hearing loss were explained about the procedure and purpose of the study. Volunteers who were willing to participate in the study were included in the study. The participants were explained about the purpose and the procedure of the study. Willing participants who had not come with their spouses were asked to bring them in the subsequent visit. Informed written consent was obtained both from the patient and their spouses. People who refused to give a written consent were not included in the study.

Patients who met the inclusion criteria were included the study. The basic sociodemographic details like the age, sex, education, employment, associated chronic ailments were noted in the patient information sheet. They were initially examined to rule out any underlying external and middle ear pathologies. Hearing was assessed initially with tuning fork test $(512 \mathrm{~Hz})$. Rinne, Weber and Absolute bone conduction test were done to clinically assess the hearing loss. Pure Tone Audiometry (PTA) was done to confirm the type and to ascertain the degree of hearing loss. Pure tone average was calculated for both ears for $500 \mathrm{~Hz}, 1000 \mathrm{~Hz}, 2000 \mathrm{~Hz}$ and $4000 \mathrm{~Hz}$. Based on the audiogram the type of hearing loss was identified. WHO classification was used to calculate the degree of hearing loss. ${ }^{9}$ The hearing loss in the better ear was taken into consideration.

The hearing status of the patient's spouse was initially assessed by doing a tuning fork test and was confirmed using pure tone audiometer. The basic sociodemographic details and associated chronic ailments were noted in the information sheet. The third party disability in the spouses was assessed using HII-SOP questionnaire. ${ }^{10}$ The questionnaire was read out to the spouse of each patient and the response was recorded.

\section{HII- SOP questionnaire: ${ }^{10}$}

The questionnaire contains 20 questions related to Social Impact, Relationship and Emotional and Communication strategies with 4,11 and 5 questions respectively. Each question has 3 possible responses: yes, sometimes or no. The responses were scored as 5, 2.5 and 0 respectively. The total disability scores and communication strategies, social impact, relation and emotion sub scores were calculated. The maximum score was 100. Scores of 20-39 were taken as mild third party disability, $40-59$ as moderate third party disability and scores $>60$ as severe disability.

\section{Data analysis:}

The degree of disability was calculated using the grading system given with the questionnaire. The correlation between the disability scores and the following variables in spouses was calculated- age, sex, employment, 
duration of hearing loss, severity of hearing loss, duration of married life and associated chronic illness.

\section{Statistical methods:}

The collected data was analysed using SPSS.23 (Statistical package for social sciences). Correlation between the severity of disability and the above mentioned factors was derived using chi square test. Statistical significance was taken at $95 \%$ confidence interval. $\mathrm{P}<0.05$ will be considered as significant.

\section{Results}

The study was done on spouses of 60 people who came to ENT department with hearing loss. The mean and the standard deviation for the age of presentation for people with hearing loss was $50.4 \pm 13.78$. The mean and the standard deviation for age of spouses was $50.1 \pm 13.36$. The range of age distribution was $23-75$ years for hearing impaired and that of their spouses were $25-72$ years.

The mean and the standard deviation for third party disability scores was $31.4 \pm 20.4$. The mean and the standard deviation for the communication strategy, relationship and emotional and social impact sub scores were $9.7 \pm 4.7,15.8 \pm 12.7$ and $6 \pm 5.7$ respectively.

The hearing loss was found to cause some degree of third party disability (58.3\%) in their spouses. (Fig. 1)

The majority of the people in the study population had a moderate hearing loss (53.3\%). Majority of people with moderate, severe or profound hearing loss had no third party disability. (Table I) There was no statistically significant association between the degree of hearing loss and the third party disability scores.

The maximum people (35\%) perceived severe handicap in domain involving communication where they had to get up, go near their partners to talk. There was no handicap for most of the people (78\%) in domain involving relationship and emotion where they had to talk less because of partner's hearing loss.

The age of presentation of study population was distributed between 20 to 79 years. Majority of patients $(92.9 \%)$ in the age group of $60-69$ years and all patients $>70$ years of age $(100 \%)$ had no handicap. More disabilities were reported in younger age groups. There was statistically significant association between the age of the spouse and the perceived disability $(\mathrm{p}=0.0001)$. (Table II)

The disability perceived by the female spouses of people with hearing impairment was more than the male spouses of people with hearing impairment. There was a statistically significant difference in the perceived disability between both the sexes $(p<0.05)$. (Table II)

Most of the spouses of people with hearing loss were working. There was no significant association between the employment status and the degree of disability. (Table II)

The presence of self perceived chronic illness in the spouse for more than a year was considered in the study. In this study people who had diabetes / hypertension/ chronic bronchitis / bronchial asthma were considered as people with chronic illness. The presence of such chronic illness in the spouse was associated with more severe disability. (Table II) There was statistically significant association between the presence of some chronic illness and the disability scores $(\mathrm{p}=0.0001)$.

As the duration of hearing loss increases the third party disability decreases. (Table II) However there is no statistically significant association between the duration of hearing loss and the disability scores.

The duration of married life was correlated with the severity of third party disability scores (Table II) Majority of the people $(63.6 \%)$ experienced moderate third party disability when the duration of married life was less than 10 years. When the duration of married life was more than 40 years, there was no self perceived third party disability.

\section{Discussion}

This study was conducted among 60 people who presented with hearing loss along with their spouses. The mean age of people who presented with hearing loss was 50.4 and their spouse was 50.1. Based on the scores obtained from the questionnaire the third party disability scores were calculated. The mean total disability scores, communication strategy sub scores, relationship and 
Table I: Distribution of study population based on the degree of hearing loss and third party disability scores:

\begin{tabular}{|c|c|c|c|c|c|c|}
\hline $\begin{array}{c}\text { DEGREE OF } \\
\text { HEARING LOSS }\end{array}$ & N & $\begin{array}{c}\text { NO } \\
\text { THIRD } \\
\text { PARTY }\end{array}$ & $\begin{array}{c}\text { MILD } \\
\text { THIRD } \\
\text { PARTY }\end{array}$ & $\begin{array}{c}\text { MODERATE } \\
\text { THIRD } \\
\text { PARTY } \\
\text { DISABILITY }\end{array}$ & $\begin{array}{c}\text { SEVERE } \\
\text { THIRD } \\
\text { PARTY }\end{array}$ \\
\hline Mild & 15 & $4(26.7 \%)$ & $2(13.3 \%)$ & $6(40 \%)$ & $3(20 \%)$ & $\chi 2=11.964$ \\
Moderate & 32 & $11(34.5 \%)$ & $9(28.2 \%)$ & $8(25 \%)$ & $4(6.3 \%)$ & 0 \\
\hline Severe & 9 & $8(88.9 \%)$ & $1(11.1 \%)$ & 0 & 0 & $0.151 \%$ \\
\hline
\end{tabular}

*Fischer exact test

Table II: Distribution of study population relating various factors with third party disability scores:

\begin{tabular}{|c|c|c|c|c|c|c|}
\hline $\mathbf{A G E}$ & $\mathbf{N}$ & $\begin{array}{l}\text { NO THIRD } \\
\text { PARTY }\end{array}$ & $\begin{array}{l}\text { MILD THIRD } \\
\text { PARTY } \\
\text { DISABILITY }\end{array}$ & $\begin{array}{c}\text { MODERATE } \\
\text { THIRD } \\
\text { PARTY } \\
\text { DISABILITY }\end{array}$ & $\begin{array}{c}\text { SEVERE } \\
\text { THIRD } \\
\text { PARTY } \\
\text { DISABILITY }\end{array}$ & \\
\hline 20-29YRS & 3 & $1(33.3 \%)$ & $\mathbf{0}$ & $1(33.3 \%)$ & $1(33.3 \%)$ & \multirow{6}{*}{$\begin{array}{c}\chi 2=46.968 \\
\text { df }=15 \\
p-0.0001 *\end{array}$} \\
\hline $30-39$ & 12 & $\mathbf{0}$ & $1(8.3 \%)$ & $8(66.7 \%)$ & $3(25 \%)$ & \\
\hline $40-49$ & 13 & $4(31 \%)$ & $3(23 \%)$ & $3(23 \%)$ & $3(23 \%)$ & \\
\hline $50-59$ & 14 & $3(21.4 \%)$ & $9(64.4 \%)$ & $1(7.1 \%)$ & $1(7.1 \%)$ & \\
\hline $60-69$ & 14 & 13(92.9\%) & $\mathbf{0}$ & $1(7.1 \%)$ & 0 & \\
\hline $70-79$ & 4 & $4(100 \%)$ & $\mathbf{0}$ & $\mathbf{0}$ & 0 & \\
\hline \multicolumn{7}{|l|}{ Sex } \\
\hline Female & 26 & $10(38.5 \%)$ & $2(7.7 \%)$ & $9(34.6 \%)$ & $5(19.2 \%)$ & \multirow{2}{*}{$\begin{array}{c}\chi 2=8.088 \\
d f=3 \\
p-0.04\end{array}$} \\
\hline Male & 34 & $15(44.1 \%)$ & $11(32.3 \%)$ & $6(17.6 \%)$ & $2(6 \%)$ & \\
\hline \multicolumn{7}{|l|}{ Employment } \\
\hline Working & 34 & $13(38.3 \%)$ & $5(14.7 \%)$ & $11(32.3 \%)$ & $5(14.7 \%)$ & \multirow{2}{*}{ 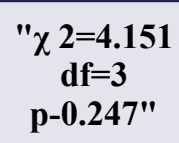 } \\
\hline Not working & 26 & $12(46.2 \%)$ & $8(30.8 \%)$ & $4(15.4 \%)$ & $2(7.7 \%)$ & \\
\hline
\end{tabular}

*Fischer exact test 
Table II (continued)

\begin{tabular}{|c|c|c|c|c|c|c|}
\hline $\begin{array}{c}\text { PRESENCE } \\
\text { OF } \\
\text { CHRONIC } \\
\text { ILLNESS }\end{array}$ & $\mathbf{N}$ & $\begin{array}{l}\text { NO THIRD } \\
\text { PARTY }\end{array}$ & $\begin{array}{l}\text { MILD THIRD } \\
\text { PARTY } \\
\text { DISABILITY }\end{array}$ & $\begin{array}{c}\text { MODERATE } \\
\text { THIRD } \\
\text { PARTY } \\
\text { DISABILITY }\end{array}$ & $\begin{array}{c}\text { SEVERE } \\
\text { THIRD } \\
\text { PARTY } \\
\text { DISABILITY }\end{array}$ & \\
\hline $\begin{array}{c}\text { No } \\
\text { associated } \\
\text { illness }\end{array}$ & 22 & $16(72.7 \%)$ & $4(18.1 \%)$ & $2(9.09 \%)$ & $\mathbf{0}$ & \multirow{2}{*}{$\begin{array}{c}\chi \begin{array}{c}2=15.388 \\
d \mathbf{f}=3 \\
p-0.001 *\end{array}\end{array}$} \\
\hline $\begin{array}{l}\text { Presence } \\
\text { of chronic } \\
\text { illness }\end{array}$ & 38 & $9(23.6 \%)$ & $9(23.6 \%)$ & $13(34.2 \%)$ & $7(18.4 \%)$ & \\
\hline \multicolumn{7}{|c|}{ Duration of hearing loss } \\
\hline $\begin{array}{l}\text { Less than } \\
1 \mathrm{yr}\end{array}$ & 19 & $4(21.1 \%)$ & $4(21.1 \%)$ & $7(36.7 \%)$ & $4(21.1 \%)$ & \multirow{4}{*}{$\begin{array}{c}\chi \begin{array}{c}2=15.381 \\
d f=12 \\
p-0.129\end{array}\end{array}$} \\
\hline $1-2$ yrs & 20 & $6(30 \%)$ & $5(25 \%)$ & $6(30 \%)$ & $3(15 \%)$ & \\
\hline $3-4 y r s$ & 13 & $9(69.2 \%)$ & $2(15.4 \%)$ & $2(15.4 \%)$ & $\mathbf{0}$ & \\
\hline 5-6yrs & 4 & $2(50 \%)$ & $2(50 \%)$ & $\mathbf{0}$ & $\mathbf{0}$ & \\
\hline \multicolumn{7}{|c|}{ Duration of married life } \\
\hline$<10$ yrs & 11 & $1(9.1 \%)$ & $1(9.1 \%)$ & $7(63.6 \%)$ & $2(18.2 \%)$ & \multirow{6}{*}{$\begin{array}{c}\chi 2=37.796 \\
\mathbf{d f}=15 \\
p-0.0001 *\end{array}$} \\
\hline 11-20yrs & 14 & $1(7.1 \%)$ & $3(21.4 \%)$ & $6(42.9 \%)$ & $4(28.6 \%)$ & \\
\hline 21-30yrs & 14 & $7(50 \%)$ & $5(35.8 \%)$ & $1(7.1 \%)$ & $1(7.1 \%)$ & \\
\hline $31-40 y r s$ & 11 & $6(54.5 \%)$ & $4(36.4 \%)$ & $1(9.1 \%)$ & $\mathbf{0}$ & \\
\hline 41-50yrs & 9 & $9(100 \%)$ & 0 & $\mathbf{0}$ & $\mathbf{0}$ & \\
\hline $\begin{array}{l}\text { More than } \\
50 \text { years }\end{array}$ & 1 & $1(100 \%)$ & 0 & 0 & 0 & \\
\hline
\end{tabular}

*Fischer exact test

emotional sub scores and social impact sub scores were $31.4,9.7,15.8$ and 6 respectively. The hearing loss in these individuals interfere with day to day activities of the spouses in spite of them having no difficulties in hearing. It affects their social life, emotional wellbeing and have communication problems as reflected by the changes in the disability scores. Almost similar results were obtained in study by Preminger et $\mathrm{al}^{10}$, where the mean total, communication, relationship and emotional and social impact disability scores were $32.87,11.62$, 18.26 and 2.99 respectively. The results were slightly higher for social impact in our study and less for the other two sub-scales. The higher impairment in social activity could be due to the reason that the mean age of the spouses were less (50.1 in comparison to 60.5) and there is an acknowledged reduction in social activity with ageing.

Most of the severe disabilities experienced by the spouses were in the areas associated with the need to use communication. Similar results were reported in other studies where communication was most commonly impaired in spouses of people with hearing loss. ${ }^{10,11,12}$ The hearing loss compromises on the effectiveness of communication. Thus, communication is the key 
element is maintaining a relationship as supported by previous studies. . $^{71,13,14,15}$

In general, it is expected that the more the hearing loss the greater will be the disability experienced by the spouse. However, in our study the severity of the hearing loss did not correlate with the severity of the disability scores as majority of our study population had mild or moderate hearing loss (only 6\% had profound hearing loss). Similar findings have been reported in study by Ask et al. ${ }^{16}$ However, in other studies the severity of the hearing loss was a predictor of the severity of the disability. ${ }^{17,18}$

The more severe handicaps are seen only with recent onset of hearing loss. The more the duration of married life, the lesser is the disability and there is no disability when the duration of married life is more than 5 years. On similar lines, in a study by Yorgason et al, the acceptance of spouses' hearing loss was deemed to be a gradual process which develops with understanding of the causes of hearing loss..$^{15}$ On the contrary, results reported by Chong et al showed that duration of hearing loss is a predictor of third party disability. ${ }^{18}$

Numerous other factors are associated with distress among the spouses of people with hearing impairment like age, ${ }^{17,18}$ sex, ${ }^{16,17,18}$ working status ${ }^{17}$ and presence of chronic aliments. ${ }^{18}$ It was also found that younger partners of people with hearing disability experienced more hearing handicap and more distress than others whereas there was no association between age and hearing handicap in studies by Knussen et a ${ }^{17}$ and Chong et al. ${ }^{18}$ It was also noted that female spouses experienced more difficulty than male spouses as noted in other similar studies $1^{6,17,18,19,20}$ because females play a more crucial role than men in maintaining communication in relationship. However, working status of the significant others did not have any association with the third party disability scores as in the study by Knussen et al. ${ }^{17}$

The nature of work was not taken into consideration in our study. The presence of any chronic ailment in the spouse was associated with more third party disability. The dysfunction caused by the underlying disease could aggravate the disability caused by their partner's hearing impairment. In a study by Chong et al, the disability scores were more with underlying self reported eye disease. ${ }^{17}$ People with higher relationship satisfaction were found to ascribe less negative attributions towards their spouses. ${ }^{19}$

The hearing loss has a significant influence not only on the patients with hearing loss but also on their spouses. The spouses have difficulties in areas where they have to use their communication skills. The spouses influence not only the quality of life but also the health seeking behaviour of the people with hearing loss and adherence to the treatment or rehabilitative measures. Taking into consideration the disability experienced by the spouse and addressing these issues will help in better rehabilitation of both the people with hearing loss and their partners.

The study involves use of a self reported questionnaire. There is no objective way of measuring third party disability. There is a possibility of under reporting or over reporting of certain items when such questionnaire is used. The study sample was essentially hospital based. Sampling from the community would give us better representation of the general population.

\section{Conclusion}

The study was conducted among spouses of 60 people with hearing loss along. The mean age of presentation was 50.4 years for people with hearing impairment and 50.1 for their spouses. From the study it can be concluded that hearing loss is associated with third party disability. There was no correlation between the degree of hearing loss and the third party disability scores. There was a significant association between the age of the spouse, duration of married life and the presence of chronic illness in the spouse with the severity of third party disability scores. Female spouses of people with hearing loss are more affected than the male spouses. There was no association between duration of hearing loss, working status of the spouses and third party disability.

The study prompts few recommendations like the need to acknowledge and address the disability in spouses of people with hearing loss, to include the spouses in treatment and rehabilitation plans and to provide couple counselling or communication education 
for the spouses thereby including speech therapists and counsellors in treatment.

Acknowledgements: We would like to thank Indian Council of Medical Research for supporting this project under ICMR STS ( Reference no: 2018- 05799).

\section{References}

1. National Sample Survey Organization. Disabled persons in India, NSS 58th round (July-December 2002) Report no.485 (58/26/1).New Delhi: National Sample Survey Organisation, Ministry of statistics and Programme Implementation, Government of India, 2003

2. World Health Organization. State of hearing and ear care in the South East Asia Region. WHO Regional Office for South East Asia. WHO-SEARO.SEA/Deaf/9. Available at http: //www. searo.who.int/LinkFiles/Publications.(accessed on 10 January 2018)

3. Garg S, Chadha S, Malhotra S, Agarwal AK. Deafness: Burden, prevention and control in India. Natl Med J India 2009; 22:79-81

4. World Health Organization. International Classification of Functioning, Disability and Health: ICF. World Health Organization; 2001

5. World Health Organization. International classification of functioning, disability and health: ICF. Geneva: World Health Organization; 2001

6. Brooks DN, Hallam RS, Mellor PA. The effects on significant others of providing a hearing aid to the hearing-impaired partner. British Journal of Audiology 2001; 35(3):165-71

7. Scarinci N, Worrall L, Hickson L. The effect of hearing impairment in older people on the spouse. International Journal of Audiology 2008;47(3):141-51

8. Stephens D, Kerr P, Jones G. Positive experiences reported by significant others of patients with hearing impairments. Audiological Medicine 2004; 2(2):134-8

9. World Health Organization Grades of hearing impairment http://www.who.int/pbd/[21] deafness/hearing_impairment_ grades/en/index.html. accessed on 12/10/2017

10. Preminger JE, Meeks S. The Hearing Impairment Impact-
Significant Other Profile (HII-SOP): A Tool to Measure Hearing Loss-Related Quality of Life in Spouses of People with Hearing Loss. Journal of the American Academy of Audiology 2012; 23(10):807-23

11. Scarinci N, Worrall L, Hickson L. The effect of hearing impairment in older people on the spouse: Development and psychometric testing of the Significant Other Scale for Hearing Disability (SOS-HEAR). International Journal of Audiology 2009;48(10):671-83

12. Schulz KA, Modeste N, Lee JW, Roberts R, Saunders GH, Witsell DL. Burden of hearing loss on communication partners and its influence on pursuit of hearing evaluation. Ear and hearing. 2017; 38(5):e285-91

13. Echalier M. In it together: the impact of hearing loss on personal relationships. Royal National Institute for Deaf People, London, UK. 2010

14. Scarinci N, Worrall L, Hickson L. Factors associated with third-party disability in spouses of older people with hearing impairment. Ear and hearing. 2012; 33(6):698-708

15. Yorgason JB, Piercy FP, Piercy SK. Acquired hearing impairment in older couple relationships: An exploration of couple resilience processes. Journal of Aging Studies 2007; 21(3):215-28

16. Ask H, Krog NH, Tambs K. Impact of hearing impairment on spousal mental health: the Nord-Trøndelag Health Study. European journal of public health 2009; 20(3):271-5

17. Knussen C, Tolson D, Swan IR, Stott DJ, Brogan CA, Sullivan F. The social and psychological impact of an older relative's hearing difficulties. Psychology, Health \& Medicine. 2004; 9(1):3-15

18. Lih CS. Third party hearing disability at pre-and post-hearing aid provision (Doctoral dissertation)

19. Anderson DL, Noble W. Couples' attributions about behaviours modulated by hearing impairment: Links with relationship satisfaction Atribuciones de las parejas acerca de las conductas moduladas por la hipoacusia: vínculos con la satisfacción de la relación de pareja. International Journal of Audiology. 2005; 44(4):197-205

20. Wallhagen MI, Strawbridge WJ, Shema SJ, Kaplan GA. Impact of self-assessed hearing loss on a spouse: A longitudinal analysis of couples. The Journals of Gerontology Series B: Psychological Sciences and Social Sciences. 2004; 59(3):S1906. 